\title{
Heritable Epigenetic Variation and its Potential Applications for Crop Improvement
}

\author{
Changqing Zhang, Tzung-Fu Hsieh*
}

Plants for Human Health Institute, Department of Plant and Microbial Biology, North Carolina State University, 600 Laureate Way, Kannapolis NC 28081, United States

\begin{abstract}
Phenotypic variation within organisms is driven primarily by genetic diversity. However, there is a growing appreciation that epigenetic variation, resulting from a multitude of diverse chemical modifications to the DNA and chromatin, can have profound effects on phenotype. Heritable epigenetic marks persist through meiosis and can be stably transmitted to the next generation, resulting in transgenerational epigenetic inheritance. Importantly, when epigenetic changes occur near coding genes, affecting their transcriptional state, heritable epigenetic variation can result in heritable phenotypic variation. Large-scale interrogation of epigenome inheritance in Arabidopsis has revealed that spontaneous variation in DNA methylation occurs at a rate that is orders of magnitude greater than genetic mutation, indicating the key importance of epigenetic variation during evolution. Thus, there is a potential for epigenetics to play a role in crop improvement, including regulation of transgene expression and creation of novel epialleles. Here, we review cases of naturally occurring and genetically induced epialleles, and discuss how the studies from two epigenetic populations are rapidly increasing our understanding of epigenetic diversity.
\end{abstract}

Keywords Epigenetics, DNA methylation, siRNA, RNA-directed DNA methylation, Transgenerational inheritance, Epiallele, Natural variation, epiRIL

\section{INTRODUCTION}

The term epigenetics is generally used to refer to the study of heritable change in gene expression that is independent of DNA sequence variation (Berger et al. 2009; Haig 2004). Such change can occur at the DNA level through DNA methylation of cytosine residues or at the level of chromatin by posttranslational modifications of histones that influence the accessibility of the DNA to transcription activation. Epigenetic changes can result in altered gene transcription, and are an important mechanism in regulating gene expression during development and in response to environmental stimulation. Such epigenetic information represents the transcriptional memory associated with cell fate decisions, developmental switches, or stress responses; memory that often needs to be erased and reset during reproduction. By contrast, transgenerational epigenetic information refers to epigenetic marks that can be stably transmitted through meiosis and inherited in the subsequent generation. Variation in this heritable epigenetic information is of particular agronomic interest as it too, like genetic variation, can result in phenotypic variation in the natural population.

The full extent to which epigenetic variation contributes to phenotypic variation remains to be determined (Richards 2011). Heritable traits that are caused by epigenetic changes are referred to as epialleles or epimutations. However, as discussed below, epialleles can be caused by genetic variations that are difficult to detect without comprehensive genome structure analysis. For example, epigenetic variation can often be caused by DNA methylation changes induced by gene duplication or transposon insertions (i.e. an obligated epiallele, Fig. 1) (Richards 2006). By contrast, pure epialleles that originate independently of any genetic variation are relatively rare (see Table 1 for summary). DNA methylation is the only epigenetic mark for which the mechanism of

Received December 11, 2013; Revised December 24, 2013; Accepted December 26, 2013; Published December 31, 2013

*Corresponding author Tzung-Fu Hsieh, thsieh3@ncsu.edu, Tel: +1-704-250-5467, Fax: +1-704-250-5425 
maintenance and stable inheritance is well understood (Law and Jacobsen 2010). Consequently, most of the naturally occurring epialleles identified and studied are associated with DNA methylation changes.

\section{DNA methylation}

DNA methylation is the addition of a methyl group to the 5-carbon of cytosine. In eukaryotic cells, this process is carried out by a family of DNA methyltransferase enzymes, which transfers methyl groups from the methyl donor S-Adenosyl methionine (SAM) to the cytosine. The resulting 5-methyl cytosine $(5 \mathrm{mC})$ is often repressive and can lead to gene silencing (Cedar and Bergman 2012). The repressive nature of $5 \mathrm{mC}$ is thought to inhibit the binding of DNA by transcription factors (Watt and Molloy 1988) or to recruit additional chromatin proteins to form heterochromatic state that is inaccessible for transcription (Cedar and Bergman 2012). DNA methylation regulates diverse biological processes including cell differentiation, X-chromosome inactivation, transposon and gene silencing, and genomic imprinting (Law and Jacobsen 2010; Reik 2007).

DNA methylation in plants occurs in the contexts of $\mathrm{CG}$, CHG and $\mathrm{CHH}(\mathrm{H}=\mathrm{A}, \mathrm{C}$, or T) (Cokus et al. 2008). DNA methylation in the CG context is carried out by METHYLTRANSFERASE1 (MET1), which is a homologue of the mammalian DNA METHYLTRANSFERASE1

Table 1. Examples of epimutation in plant.

\begin{tabular}{|c|c|c|c|c|c|}
\hline Target & Trigger & Epigenetic Effect & Species & Phenotype & References \\
\hline$C m W I P 1$ & $h A T$ insertion & $\begin{array}{l}\text { Spreading of DNA methylation } \\
\text { to } C m W I P 1\end{array}$ & C. melo & $\begin{array}{l}\text { Promote female } \\
\text { flower }\end{array}$ & $\begin{array}{l}\text { Martin et al. } \\
2009\end{array}$ \\
\hline$F W A$ & SINE insertion & $\begin{array}{l}\text { SINE DNA methylation and } \\
\text { silencing of } F W A\end{array}$ & $\begin{array}{l}\text { Arabidopsis } \\
\text { genus }\end{array}$ & Late flowering & $\begin{array}{l}\text { Soppe et al. } \\
2000\end{array}$ \\
\hline $\begin{array}{l}\text { BONSAI } \\
(B S N) \\
\end{array}$ & $d d m 1$ & $\begin{array}{l}\text { Spreading of DNA methylation } \\
\text { from LINE to BSN gene }\end{array}$ & A. thaliana & Stunted growth & $\begin{array}{l}\text { Saze and } \\
\text { Kakutani } 2007\end{array}$ \\
\hline booster 1 & $\begin{array}{l}\text { MITE repeats at } \\
\text { upstream } \\
\text { enhancer }\end{array}$ & Paramutagenic & Z. mays & Pigmentation & $\begin{array}{l}\text { Stam et al. } \\
2002\end{array}$ \\
\hline PAI genes & $\begin{array}{l}\text { PAII-PAI4 } \\
\text { inverted repeat }\end{array}$ & $\begin{array}{l}\text { DNA methylation and silencing } \\
\text { of all } A P I \text { genes }\end{array}$ & A. thaliana & $\begin{array}{l}\text { Heavy methylation } \\
\text { of all } A P I \text { genes }\end{array}$ & $\begin{array}{l}\text { Bender and } \\
\text { Fink } 1995 \\
\end{array}$ \\
\hline FOLT1 & $\begin{array}{l}\text { FOLT2 complex } \\
\text { duplication }\end{array}$ & $\begin{array}{l}\text { DNA methylation and silencing } \\
\text { of FOLT1 }\end{array}$ & A. thaliana & Reduced fertility & $\begin{array}{l}\text { Durand et al. } \\
2012\end{array}$ \\
\hline $\begin{array}{l}\text { SUPERMAN } \\
\text { (SUP) }\end{array}$ & $\begin{array}{l}\text { Mutagenesis } \\
\text { screens }\end{array}$ & $\begin{array}{l}\text { DNA methylation and silencing } \\
\text { of } S U P\end{array}$ & A. thaliana & $\begin{array}{l}\text { Floral organ } \\
\text { defects }\end{array}$ & $\begin{array}{l}\text { Jacobsen and } \\
\text { Meyerowitz } \\
1997\end{array}$ \\
\hline$L c y c$ & $\begin{array}{l}\text { Naturally } \\
\text { occurring }\end{array}$ & $\begin{array}{l}\text { DNA methylation and silencing } \\
\text { of } L c y c\end{array}$ & L. vulgaris & $\begin{array}{l}\text { Change in floral } \\
\text { symmetry }\end{array}$ & $\begin{array}{l}\text { Cubas et al. } \\
1999\end{array}$ \\
\hline CNR & $\begin{array}{l}\text { Naturally } \\
\text { occurring }\end{array}$ & $\begin{array}{l}\text { DNA methylation and silencing } \\
\text { of } C N R\end{array}$ & S. lycopersicum & $\begin{array}{l}\text { Fruit ripening } \\
\text { defect }\end{array}$ & $\begin{array}{l}\text { Manning et al. } \\
2006\end{array}$ \\
\hline OsSPL14 & $\begin{array}{l}\text { Naturally } \\
\text { occurring }\end{array}$ & $\begin{array}{l}\text { OSSPL14 Promoter } \\
\text { hypomethylation }\end{array}$ & O. sativa & $\begin{array}{l}\text { Panicle branching } \\
\text { and higher grain } \\
\text { yield }\end{array}$ & $\begin{array}{l}\text { Miura et al. } \\
2010\end{array}$ \\
\hline $\begin{array}{l}\text { DWARF1 } \\
\text { (D1) }\end{array}$ & $\begin{array}{l}\text { Naturally } \\
\text { occurring }\end{array}$ & $\begin{array}{l}\text { DNA methylation and silencing } \\
\text { of } D 1\end{array}$ & O. sativa & Dwarf & $\begin{array}{l}\text { Miura et al. } \\
2009\end{array}$ \\
\hline OsFIE1 & $\begin{array}{l}\text { Naturally } \\
\text { occurring }\end{array}$ & $\begin{array}{l}\text { OSFIE1 Promoter } \\
\text { hypomethylation and ectopic } \\
\text { OSFIE1 expression }\end{array}$ & O. sativa & Dwarf & $\begin{array}{l}\text { Zhang et al. } \\
2012 b\end{array}$ \\
\hline
\end{tabular}


(DNMT1) (Vongs et al. 1993). Arabidopsis met1 mutant has very little CG methylation and displays defects in morphology and fertility (Law and Jacobsen 2010; Zemach et al. 2010b). CHG methylation in Arabidopsis is maintained by the plant-specific DNA methyltransferase CMT3 whose chromodomain recognizes and binds to H3K9me2 marks (Bartee et al. 2001; Johnson et al. 2007; Lindroth et al. 2001). Both CG and CHG sites are symmetrical in that similar sequences exist on the complementary DNA strand. Upon DNA replication, hemi-methylated CG and CHG sites are recognized, and methylation on the newly synthesized strand is restored by MET1 and CMT3, respectively.

By contract, methylation of the $\mathrm{CHH}$ sites has to be established and maintain by the siRNA directed DNA methylation (RdDM) pathway (Henderson and Jacobsen 2007; Matzke et al. 2009; Wassenegger et al. 1994). Lack of siRNAs leads to progressive loss of methylation on $\mathrm{CHH}$ sites. The production of siRNAs involves three core components: DNA-dependent RNA-Polymerase IV (Pol IV), RNA-dependent RNA Polymerase 2 (RDR2) and endoribonuclease DICER-LIKE 3 (DCL3). Pol IV preferentially targets transposons and repetitive elements to produce single-stranded RNA. The RNA was replicated by RDR2 to form double-stranded RNA, which is then processed by DCL3 into 24-nucleotide siRNAs. During de novo methylation, plant-specific RNA Polymerase V (PolV) and associated factors produce nascent transcripts from target loci that are recognized by siRNA-containing AGO4 complexes and recruit DRMs de novo methyltransferases to target loci for DNA methylation (Haag Pikaard 2011).

DNA methylation is an evolutionarily ancient process that is associated with gene silencing in eukaryotes. It has long been proposed to function as a genomic defense mechanism against invading transposable elements (TEs) (Law and Jacobsen 2010). DNA methylation is generally observed in heterochromatic regions like centromeres and pericentromeres, which consist mainly of TEs and repeats, and is the major epigenetic silencing mechanism to ensure their immobility (Law and Jacobsen 2010; Li et al. 2008; Wang et al. 2009; Zhang et al. 2006; Zilberman et al. 2007). DNA methylation is also seen in TEs and repeats in euchromatic regions, including coding sequences (Cokus et al. 2008; Zilberman et al. 2007). DNA methylation is crucial for proper development. Defects in DNA methylation lead to embryonic lethality in mammals and developmental defects in plants. DNA hypermethylation in promoter or near transcription start sites can result in transcriptional silencing, and promoter demethylation and concomitant transcriptional activation has been demonstrated for many imprinted genes in plants (Gehring et al. 2006; Gehring et al. 2009; Hsieh et al. 2009; Hsieh et al. 2011; Waters et al. 2013; Waters et al. 2011; Zemach et al. 2010a).

\section{Transgene silencing}

Transgenic plants are routinely generated for crop improvement or for research purposes. The expression level of transgenes varies greatly among independent transgenic lines (Holtorf et al. 1995; Jones et al. 1985; Peach and Velten 1991). This variation is caused by many factors, including insertion location, copy number, and orientation of the inserted transgene. Desirable transgenic lines can be evaluated and selected from multiple transgenic lines. However, the transgene may become silenced in following generations, posing a more serious challenge in applying genetic engineering to crop breeding.

Transgene silencing is a typical epigenetic phenomenon that attracts broad attention. Although many questions remain, much has been learned about the molecular mechanisms of transgene silencing. Transgenes may be silenced at transcriptional level (transcriptional gene silencing, TGS), or at posttranscriptional level (posttranscriptional gene silencing, PTGS). A classic example of PTGS is sense-cosuppression observed in petunia (Napoli et al. 1990; Que et al. 1997). In transgenic petunia plants overexpressing a rate-limiting enzyme for anthocyanin production, the transgene and endogenous gene are simultaneously silenced, converting uniformly pigmented flowers to completely white or patterned flowers. The underlying mechanism is that the transgene mRNA is processed into abundant trans-acting siRNAs (tasiRNAs), which target and cleave the transcripts of both transgene and endogenous gene (De Paoli et al. 2009). Transgene silencing through PTGS is often less stable, because the process is reset at certain developmental stages in each 
generation. By contrast, when a transgene is transcriptionally silenced, the silent state is often stably inherited across generations. This is because DNA methylation in the promoter or downstream regulatory sequences is a common cause for TGS, and as discussed above, symmetric CG methylation is faithfully maintained across generations (Dalakouras et al. 2012; Mathieu et al. 2007). In addition, during gametogenesis and early seed development, mechanisms exist to reinforce DNA methylation through RdDM on the gamete genomes (Hsieh et al. 2009; Mirouze et al. 2009; Slotkin et al. 2009).

\section{Epimutations induced by genetic variation}

Many of the known epimutations are induced by TE insertions or genome structural variation such as gene duplication. For example, insertion of a $h A T$ transposon near the transcription factor gene $C m W I P 1$ induces DNA hypermethylation and transcription silencing of the CmWIP1 gene in melon (Fig. 1 (A); Martin et al. 2009). Expression of CmWIP1 leads to carpel abortion and promotes development of male flowers while silencing of CmWIP1 gene suppresses anther development and produces female flowers. Thus the methylation state of CmWIP1 gene determines the unisexual nature of melon flower. Consistent with the nature of epimutations, silent CmWIP1 locus occasionally reverts to active state with reduced DNA methylation and reverted floral phenotype.

The Arabidopsis FLOWERING WAGENINGEN (FWA) gene is only expressed in endosperm from the maternal genome, but is transcriptionally silenced in embryo and in all other developmental stages (Kinoshita et al. 2004). In wild-type plants, $F W A$ is silenced due to DNA hypermethylation of the SHORT INTERSPERSED ELEMENTS (SINES) in the 5' regulatory region, and plants flower early. In fwa epimutant, SINEs DNA methylation is lost and FWA is de-repressed, causing significant delay in flowering time (Fig. 1 (B); Kinoshita et al. 2007; Soppe et al. 2000). A sequence survey revealed that SINE repeats structure in the FWA promoter is highly diverse among Arabidopsis accessions, indicating each repeat insertion derived independently (Fujimoto et al. 2008).

Another well-studied epiallele, bonsai ( $b s n)$, was isolated as a $d d m 1$ induced epimutation. DDM1 encodes a
SWI/SNF-like ATP-dependent chromatin remodeler, and is required for maintenance of DNA methylation in Arabidopsis (Jeddeloh et al. 1999; Lippman 2004). Loss of DNA methylation in $d d m 1$ background de-repressed a non-LTR retroelement located downstream of the BSN coding sequence, resulting in hypermethylation and silencing of $B S N$ gene (Fig. 1(C); Saze and Kakutani 2007). Although bonsai is not a natural epimutant, it was reproducibly induced during self-pollination of the $d d m 1$ mutant. Its discovery suggests the existence of cryptic epigenetic variation in plant. The molecular phenotype, increase in BONSAI methylation or $i b m$, can be phenocopied by mutations in a jmjC domain containing gene IBMI which encodes a $\mathrm{H} 3 \mathrm{~K} 9 \mathrm{me} 2$ demethylase that functions to block non-CG methylation in genic sequences (Saze et al. 2008).

Paramutation involves communication between homologous loci in trans, and results in altered DNA methylation and heritable chromatin change. One of the best-studied paramutation systems is the maize boosterl (bl) gene. The paramutable $B-I$ allele is active and causes intense pigmentation, whereas the paramutagenic $B^{\prime}$ is weakly transcribed with little pigmentation. In hybrids between $B-I$ and $B^{\prime}$, the transcription and chromatin state of $B-I$ allele is converted to that of the $\mathrm{B}^{\prime}$ allele, causing a dramatic decrease in pigment production. The change of $B-I$ to $B^{\prime}$ is heritable and the newly converted $B$ 'becomes paramutagenic. A tandem repeat of seven MITEs in an enhancer region located $100-\mathrm{kb}$ upstream of the $b 1$ coding sequence has been shown to be required for paramutation. The MITE repeats are hypomethylated in the paramutable $B-I$ allele and hypermethylated in the paramutagenic $B$ ' allele (Fig. 1 (D); Haring et al. 2010; Stam et al. 2002). Genetic and molecular studies indicate that components of the RdDM pathway are required for the maintenance of paramutagenic states in maize (Alleman et al. 2006; Erhard et al. 2009; Hale et al. 2009; Hollick et al. 2005; Stonaker et al. 2009). Interestingly, transgenes carrying $b 1$ enhancer repeats can ectopically convert $B-I$ into paramutagenic $B^{\prime}$ state, providing insights into possible applications for crop improvement (Belele et al. 2013).

In addition to TEs and repeats induced epigenetic variation, gene duplication and rearrangement can also 
induce epigenetic changes. In Arabidopsis Columbia (Col) ecotype, the PHOSPHORIBOSYL ANTHRANILATE ISOMERASE (PAI) gene family of the tryptophan biosynthesis pathway contains three unlinked genes, $P A I 1$, $P A I 2$, and $P A I 3$. But in Wassilewskija (Ws) ecotype an additional copy, $P A I 4$, is present in a tail-to-tail orientation with $P A I 1$, and all four loci carry heavy DNA methylation.
Mutant plants with the PAII-PAI4 locus deleted have reduced DNA methylation at remaining $P A I 2$ and $P A I 3$ loci, indicating their methylation is caused by PAI1-PAI4 (Fig. 1(E); Bender and Fink 1995). Further experiments confirmed that the PAI1-PAI4 inverted repeats induce DNA methylation of all $P A I$ genes via RdDM (Bender 2004).
(A)

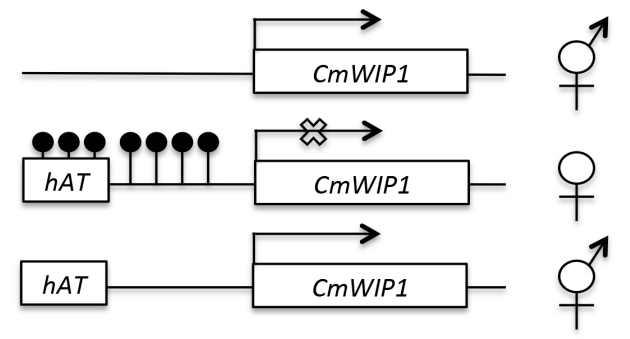

(B)

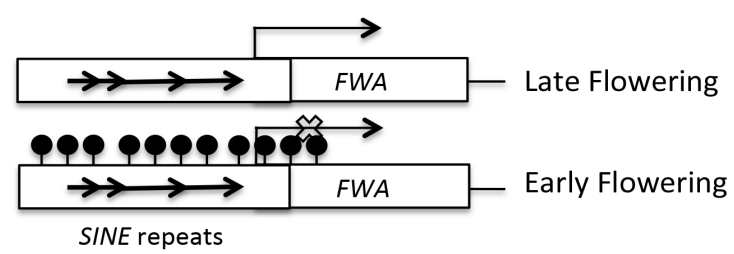

(C)

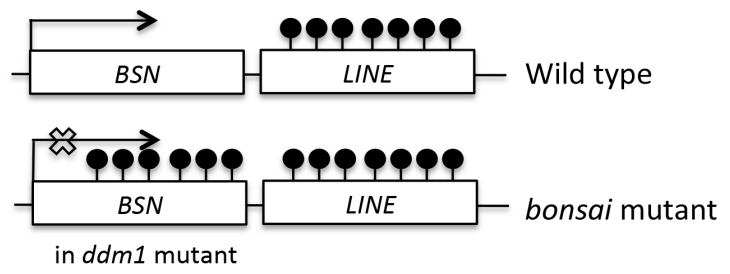

(D)

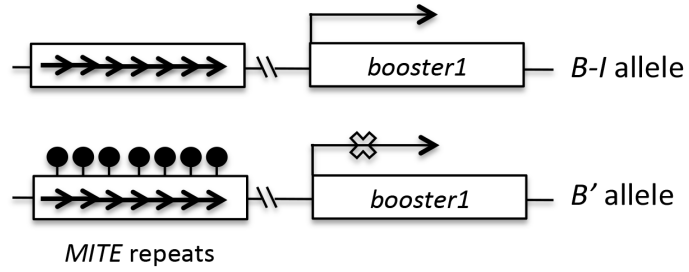

(E)

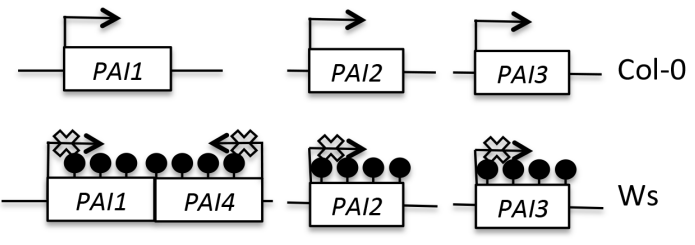

(F)

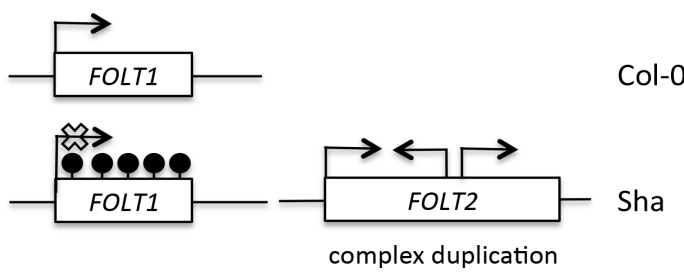

Fig. 1. Mechanisms of epimutation induced by genetic variation.

(A) Insertion of the $h A T$ transposon upstream of the $C m W I P 1$ gene led to DNA hypermethylation and silencing of $C m W I P 1$ gene, resulting in inhibition of male sexual organs development in melon. Reversion by loss of DNA methylation restores bi-sexual flower development.

(B) In wild-type Arabidopsis, SINE elements near $F W A$ promoter are methylated and $F W A$ is silenced, resulting in early flowering. In the fwa epiallele, SINE elements are hypomethylated and $F W A$ is de-repressed, resulting in late flowering.

(C) In wild-type Arabidopsis, LINE elements next to BONSAI $(B S N)$ gene are methylated. In $d d m 1$ mutants, LINE DNA methylation spreads toward $B S N$ coding sequences, causing DNA hypermethylation and silencing of $B S N$.

(D) The paramutagenic $B^{\prime}$ allele contains seven methylated MITE repeats in an enhancer region 100-kb upstream of the boosterl (bl) gene whereas in the paramutable $B-I$ allele, the MITE repeats are hypomethylated. When both $B^{\prime}$ and $B-I$ are present, the active $B$ - $I$ allele is converted to the inactive $B^{\prime}$ state in a stable and heritable fashion.

(E) The Arabidopsis Col-0 ecotype has 3 unlinked, active PAI1, PAI2, PAI3 genes. In WS ecotype, an extra copy, PAI4, is present in a tail-to-tail orientation with $P A I 1$. This $P A I 1-P A I 4$ inverted repeat induces heavy DNA methylation in all four WS $P A I$ genes.

(F) In Sha accession, FOLT2 is a complex duplicated locus with multiple truncated copies that produces siRNAs and silence FOLT1 by RdDM. By contrast, Col-0 only has an active FOLT1 copy and lacks FOLT2. This copy number induced epigenetic variation was not revealed until close examination of sterile RIL progenies that inherited only the silenced FOLT1 from Sha, and chromosome segments from Col-0 that lacks FOLT2. 
Another example of epigenetic variation induced by gene duplication is involved in genetic incompatibility between Col-0 and Shahdara (Sha) ecotypes. Col-0 has only one copy of the FOLATE TRANSPORTER gene, FOLT1, on chromosome 5 while Sha has an additional copy, FOLT2, on chromosome 4 . The FOLT2 is a complex locus with multiple truncated copies that produces siRNAs and silence FOLT1, but not FOLT2, in Sha. In a recombinant inbred line (RIL) population generated from a cross between Sha and Col-0, the silent FOLT1 is stable in the absence of silencing inducer FOLT2. The RILs that inherited the silenced FOLT1 copies from Sha, and chromosome 5 segments from Col-0 that lacks FOLT2, have reduced fertility due to lack of FOLT activity (Fig. 1 (F); Durand et al. 2012).

\section{Epimutations that are not accompanied by genetic changes}

One of the first plant epiallele was clark kent (clk) in Arabidopsis, which exhibits DNA hypermethylation at the SUPERMAN locus. The $c l k$ epiallele has phenotypes similar to loss-of-function mutants of SUPERMAN, with increased numbers of stamens and carpels. The unstable $c l k$ epiallele can revert back to normal phenotypes, and is accompanied by a reduction in DNA methylation at the SUPERMAN locus (Jacobsen and Meyerowitz 1997). Another example was a naturally occurring mutant of Linaria vulgaris, peloric, which changed the symmetry of the flower from bilateral to radial. The mutant flower is caused by promoter hypermethylation and silencing of LCyc, a CYCLOIDEA gene homolog known to regulate floral asymmetry in Antirrhinum. The resulting epimutant has been stably maintained for hundreds of years. Consistent with the nature of an epiallele, mutant flowers occasionally reverted back to wild-type flowers, which are accompanied by loss of hypermethylation in Lcyc gene (Cubas et al. 1999).

The tomato fruit-ripening mutant colorless non-ripening, $c n r$, is a well characterized, naturally occurring epiallele of $C N R$, which encodes an SBP-box transcription factor. In this mutant, a segment of $C N R$ promoter is hypermethylated, resulting in silencing of $C N R$ expression and inhibition of normal ripening (Manning et al. 2006). Using chromatin immunoprecipitation approach, the MADS-box transcription factor RIPENING INHIBITOR (RIN), an essential ripening regulator, was shown to interact with the promoters of genes important for the ripening processes, including $C N R$ (Martel et al. 2011). Interestingly, the binding of RIN to the CNR promoter is greatly reduced in $c n r$ mutant (Martel et al. 2011), supporting the model that DNA hypermethylation inhibits transcription by preventing binding of transcription factors.

Several epialleles affecting development or agronomic traits have been discovered in rice. The quantitative trait locus WEALTHY FARMERS PANICLE (WFP) encodes OsSPL14, was shown to promote panicle branching and higher grain yield in rice. The rice strain ST-12 that carries OSSPL14 ${ }^{W F P}$ trait has much higher expression of OSSPL14 in young panicles compared to Nipponbare. While no sequence variation was detected around OSSPL14 gene in these two strains, several cytosines in the promoter were found to have high DNA methylation in Nipponbare, correlating with its lower expression level (Miura et al. 2010). The rice epi- $d l$ allele showed DNA hypermethylation and epigenetic silencing of the DWARF1 (D1) gene. The silenced state is associated with repressive histone and DNA methylation marks. The epi-dl epiallele is not stable and its dwarf phenotype correlates with DNA methylation and down-regulation of $D 1$ expression (Miura et al. 2009). The epimutation of OsFIE1, epi-df, is caused by DNA hypomethylation in the promoter, and ectopic expression, of OSFIE1 gene. Ectopic expression of OSFIE1 gene is also accompanied by reduced $\mathrm{H} 3 \mathrm{~K} 9 \mathrm{me} 2$ and increased $\mathrm{H} 3 \mathrm{~K} 4 \mathrm{me} 3$ levels, and resulted in alternation of $\mathrm{H} 3 \mathrm{~K} 27 \mathrm{me} 3$ levels in hundreds of genes and a heritable dwarf phenotype (Zhang et al. 2012b).

\section{Environment induced epigenetic variation}

Plants, being sessile, must respond to environmental stresses through physiological changes. It is well documented that chromatin modifications play a role in plants' response to environmental stimuli. More recently, a growing number of reports have demonstrated potential change in DNA methylation can be induced by various biotic and abiotic stresses (Lang-Mladek et al. 2010; Pecinka et al. 2010; Tittel-Elmer et al. 2010). In order for the environmental 
stimuli to induce stable epigenetic change, the perceived stimuli must be propagated and perpetuated through cell divisions. Several studies looked at the stability of epigenetic states under various stress conditions and found that silencing of reporter transgenes, as well as endogenous loci, is released upon various abiotic stresses such as high salinity, draught, heat, or UV radiation (Lang-Mladek et al. 2010; Pecinka et al. 2010; Tittel-Elmer et al. 2010). However, such stress-induced transcriptional activation is mostly transient, and silencing is rapidly restored upon returning to optimal growth conditions. Other studies suggest a more widespread and potentially stable DNA methylation changes among different environmental conditions. Lira-Medeiros et al. (2010) applied methylation sensitive amplification polymorphism (MSAP) method to study genetic and epigenetic ( $\mathrm{CpG}$ methylation) variation in two mangrove tree populations grown in different water stress environments. Trees grown adjacent to river are larger, taller, and have higher $\mathrm{CpG}$ methylation compared to trees grown in nearby high salinity ground. Interestingly, cytosine methylation polymorphism is greater than genetic variation, in both populations. Colaneri and Jones (2013) simulated drought condition and examined DNA methylation and transcription profile changes in Arabidopsis seedlings. Among the $\sim 1,000$ genes with expression level changes, 316 showed altered DNA methylation level near their transcriptional start sites. Jin et al. (2013) found substantial changes in DNA methylation in the promoter regions of the ETHYLENE RESPONSIVE FACTOR 6 (ERF6), SUPPRESSION OF RVS 161 DELTA 4 (SUR4) and 3-KETOACYL-COA SYNTHASE 13 (KCS13), which regulate cotton fiber growth, over the course of one year. Together these observations suggest a dynamic DNA methylation plasticity in response to growth environments.

Biotic stress is widely studied environmental effects that have also been implicated in changing DNA methylation and creating heritable epigenetic variation. Using the apomictic dandelions that reproduce through unfertilized seeds, Verhoeven et al. (2010) examined epigenetic alterations induced by various biotic stresses in the absence of genetic variation. The authors used MSAP to profile DNA methylation difference among dandelion populations that were treated with chemicals to induce herbivore and pathogen defenses, and found considerable methylation variation throughout the genome. Furthermore, many DNA methylation changes can be faithfully transmitted to the subsequent generation, suggesting that stress-induced methylation changes are common and can be heritable. Luna et al. (2012) showed that Arabidopsis exposed to pathogens induces systemic acquired resistance (SAR) and produces progeny that are primed for defense response, indicating a transgenerational inheritance of SAR response. Supporting the observation, genome-wide DNA methylation and transcription profiling identified widespread DNA methylation, and associated gene expression changes in response to biotic stress (Dowen et al. 2012).

Stress-induced epigenetic variation can also arise from activation and mobilization of transposons. The genomes of higher plants consist mainly of TEs and repeats. For example, up to $85 \%$ of the maize genome is composed of TEs, particularly the retroelements (Schnable et al. 2009). Thus keeping majority of the genome epigenetically silenced is a daunting task and requires a suite of robust and highly regulated silencing mechanisms. Thus it is not surprising to find that even in global DNA hypomethylation mutant met 1 or $d d m 1$ backgrounds, many TEs are derepressed but rarely mobilized (Tsukahara et al. 2009). As discussed earlier that heat stress destabilizes transcriptional gene silencing, the Arabidopsis retroelement ONSEN was transcriptionally activated in response to heat stress, resulting in synthesis and accumulation of extrachromosomal ONSEN DNA copies. Significantly, a high frequency of new ONSEN insertions was observed in the progeny of stressed siRNA pathway mutants, but not in stressed wild-type progeny. Furthermore, ONSEN insertions confer heat responsiveness to nearby genes. Thus, stress-induced epigenetic changes and mobilization of TEs can confer new regulatory circuitry to nearby genes, generating novel phenotypic traits (Ito et al. 2011). These observations resemble the Sicilian blood orange that arose from an insertion of a copia-like retrotransposon adjacent to a gene encoding RUBY, a MYB transcription activator of anthocyanin production. The retrotransposon provides a regulatory network that confers cold dependency of $R U B Y$ expression (Butelli et al. 2012). 


\section{Unlocking the epigenome for crop improvement}

Throughout the life cycle, organisms are constantly exposed to chemicals, nutritional deficiency, or subject to influence of maternal behavior shown to cause altered gene expression that can persist and sometimes be transmitted to the next generation (Anway et al. 2005; Cooney et al. 2002; Dolinoy et al. 2006; Kaminen-Ahola et al. 2010; Vandegehuchte et al. 2010; Weaver et al. 2004). In honeybees, larvae fed with royal jelly develop into queens while larvae fed with regular food become worker bees. Experimental down-regulation of a honeybee DNA methyltransferase Dnmt 3 can result in increased number of queens from the larvae not fed with royal jelly, indicating that nutritional input stored as epigenetic information can be used for developmental decision-making in insect (Kucharski et al. 2008). Similarly, the variable yellow agouti $\left(A^{v y}\right)$ mouse whose coat color variation correlates with epigenetic marks established early in development, has been used to study the impacts of nutritional and environmental influences on the epigenome of the fetus. Animal fed with methyl-rich diet such as folic acid has higher DNA methylation level at the $A^{v y}$ locus, and ethanol exposure led to transcriptional silencing and hypermethylation at the $A^{v y}$ locus (Dolinoy 2008; Dolinoy et al. 2006; Kaminen-Ahola et al. 2010; Waterland and Jirtle 2003; Waterland et al. 2007). These observations indicate that modulating expression of epigenetic maintenance enzymes such as DNA methyltransferases or methyl donor SAM biosynthesis genes can have profound effects on the integrity of epigenome. Indeed, several recent chemical genomic screens have identified small molecular compounds that can suppress epigenetic silencing of transgene reporters. Intriguingly, folic acid metabolism and the methyl donor SAM biosynthesis pathway are frequent targets of these small molecule inhibitors (Dinh et al. 2013; Noutoshi et al. 2012; Zhang et al. 2012a).

Attempts to generate epigenetic diversity in crop species have been hindered by the lack of global DNA methylation mutants such as met 1 and $d d m 1$. Instead, chemical inhibition of epigenetic maintenance or regulation provides an attractive alternative. Akimoto et al. (2007) subjected rice seeds to methylation inhibitor 5-azadeoxycytidine treatments during germination. The surviving progenies were propagated in the field for over 10 years, and some of the altered phenotypic characters were stably inherited, including a line that showed acquired resistance to a bacterial pathogen Xanthomonas oryzae due to promoter DNA hypomethylation and induced expression of a disease resistant gene $\mathrm{Xa2} 1 \mathrm{G}$.

By contrast, rapid progress has been made in unveiling phenotypic diversity and plasticity masked in wild type Arabidopsis by DNA methylation. In particular, there is a great deal of interest and excitement in the comprehensive analyses of epigenetic diversity using recombinant inbred populations generated from parental strains that differed only in DNA methylation. These so called "epi-recombinant inbred lines", or epiRILs, were created by crossing DNA methylation mutants (i.e., met1 and $d d m 1$ ) to wild-type plants. The resulting inbred lines carry homozygous, epigenetically diverge genomic segments inherited from wild-type and hypomehtylated parents. The epiRILs displayed variable and heritable morphological or developmental traits, including flowering time, plant height, biomass, TE mobilization, salt and pathogen responses (Johannes et al. 2009; Reinders et al. 2009). Examining the DNA methylation profiles of individual epiRILs confirmed that segments of parent-specific epi-alleles are visible and can be maintained within the epiRILs for at least eight generations (Reinders et al. 2009). Together these studies provided conceptual and technological breakthrough to our understanding, and potential application, of epigenetic variation and inheritance. They also provide the first insight into the extent of phenotypic variation generated by random combination of parent-specific epigenomes. It is thus likely that heritability of epigenetic variation can contribute to a significant degree in complex phenotypic traits. Supporting the theory, when a larger panel of epiRILs was tested under ecologically realistic conditions, they were found to display heritable phenotypic diversity and exhibit heritability patterns resembling those of the natural accessions in most of the traits examined (Roux et al. 2011). In another independent study, epiRILs were tested for responses to biotic stress induced by jasmonic acid and salicylic acid, and found to carry significant heritable variations in growth rates and in responses to defense hormones (Latzel et al. 2012). Furthermore, when biomass, response to drought, and nutrient ability were considered as traits of ecological 
importance, epiRILs further confirm the notion that variations in DNA methylation can cause substantial heritable variations of these ecologically important traits, suggesting possible evolutionary selection on epigenetic variation (Latzel et al. 2013; Zhang et al. 2013).

\section{Frequency of spontaneous epigenetic variation}

The meiotically heritable epialleles discussed above, such as peloric and $c n r$, are thought to occur spontaneously in their respective populations. However, it is not possible to know how frequent such spontaneous heritable epialleles could arise in the natural population.

Using model plant Arabidopsis, two recent studies provided an intriguing answer to the question. Both studies used whole genome methylation sequencing technique to examine spontaneously occurring variation in DNA methylation at base-pair resolution by comparing plants propagated by single-seed descent for 30 generations. Significantly, both studies found that the rate of spontaneous variation in DNA methylation was at least four orders of magnitude greater than spontaneous genetic mutations (Schmitz et al. 2011; Becker et al. 2011). On average, about $10 \%$ of all methylated cytosines have increased or decreased methylation in at least one of the progenies examined (Becker et al. 2011). Interestingly, the distribution of these differentially methylated cytosines is not random, and overlaps significantly with loci that are affected by met 1 or RdDM mutations (Schmitz et al. 2011), suggesting incomplete reinforcement of methylation states is a major factor in generating spontaneous epialleles.

\section{CONCLUSION}

Genetic diversity has long been considered as the main foundation for phenotypic variation. As a result, the design of breeding programs has traditionally focused on genetic variation. The lessons learned from epiRIL and related epigenetic studies strongly indicates a great deal of epigenetic variation is associated with phenotypic diversity. These studies also suggest previously observed phenotypic diversity in genetic based studies might have a stronger epigenetic attribution, and warrant further re-evaluation. However,
epiRIL based study in major crop species is still not possible without global DNA methylation mutants such as met 1 and $d d m 1$ in Arabidopsis. Inhibiting DNA methylation or other histone modifications by small molecule inhibitors can provide feasible alternatives as exemplified by the rice DNA methylation inhibition study (Akimoto et al. 2007).

It is conceivable that in future design of breeding programs, epigenetic variation will increasingly be taken into consideration. Particularly with the advance of genomic technologies and reducing cost for high throughput DNA sequencing, epigenetic marker-assisted breeding strategies can be applied to select for agronomical desirable epigenetic quantitative traits. Crop improvement via locus-specific epigenetic manipulation has become increasingly feasible with continuing improvement of TALE- or CRISPR-based genome editing technologies (Chen Gao 2013; Maeder et al. 2013; Mendenhall et al. 2013).

\section{REFERENCES}

Akimoto K, Katakami H, Kim HJ, Ogawa E, Sano CM, Wada Y, Sano H. 2007. Epigenetic inheritance in rice plants. Ann. Bot. 100: 205-217.

Alleman M, Sidorenko L, McGinnis K, Seshadri V, Dorweiler JE, White J, Sikkink K, Chandler VL. 2006. An rnadependent rna polymerase is required for paramutation in maize. Nature 442: 295-298.

Anway MD, Cupp AS, Uzumcu M, Skinner MK. 2005. Epigenetic transgenerational actions of endocrine disruptors and male fertility. Science 308: 1466-1469.

Bartee L, Malagnac F, Bender J. 2001. Arabidopsis cmt3 chromomethylase mutations block non-cg methylation and silencing of an endogenous gene. Genes Dev. 15: 1753-1758.

Becker C, Hagmann J, Muller J, Koenig D, Stegle O, Borgwardt K, Weigel D. 2011. Spontaneous epigenetic variation in the arabidopsis thaliana methylome. Nature 480: 245-249.

Belele CL, Sidorenko L, Stam M, Bader R, Arteaga-Vazquez MA, Chandler VL. 2013. Specific tandem repeats are sufficient for paramutation-induced trans-generational silencing. PLoS Genet. 9: e1003773.

Bender J. 2004. DNA methylation and epigenetics. Annu. Rev. Plant Biol. 55: 41-68. 
Bender J, Fink GR. 1995. Epigenetic control of an endogenous gene family is revealed by a novel blue fluorescent mutant of arabidopsis. Cell 83: 725-734.

Berger SL, Kouzarides T, Shiekhattar R, Shilatifard A. 2009. An operational definition of epigenetics. Genes Dev. 23: 781-783.

Butelli E, Licciardello C, Zhang Y, Liu J, Mackay S, Bailey P, Reforgiato-Recupero G, Martin C. 2012. Retrotransposons control fruit-specific, cold-dependent accumulation of anthocyanins in blood oranges. Plant Cell 24: 1242-1255.

Cedar H, Bergman Y. 2012. Programming of DNA methylation patterns. Annu. Rev. Biochem. 81: 97-117.

Chen K, Gao C. 2013. Targeted genome modification technologies and their applications in crop improvements. Plant Cell Rep. doi:10.1007/s00299-013-1539-6.

Cokus SJ, Fing S, Zhang X, Chen Z, Merriman B, Haudenschild CD, Pradhan S, Nelson SF, Pellegrini M, Jacobsen SE. 2008. Shotgun bisulphite sequencing of the arabidopsis genome reveals DNA methylation patterning. Nature 452: 215-219.

Colaneri AC, Jones AM. 2013. Genome-wide quantitative identification of DNA differentially methylated sites in arabidopsis seedlings growing at different water potential. PLoS One 8: e59878.

Cooney CA, Dave AA, Wolff GL. 2002. Maternal methyl supplements in mice affect epigenetic variation and DNA methylation of offspring. J. Nutr. 132: 2393S-2400S.

Cubas P, Vincent C, Coen E. 1999. An epigenetic mutation responsible for natural variation in floral symmetry. Nature 401: 157-161.

Dalakouras A, Dadami E, Zwiebel M, Krczal G, Wassenegger M. 2012. Transgenerational maintenance of transgene body cg but not chg and chh methylation. Epigenetics 7: 1071-1078.

De Paoli E, Dorantes-Acosta A, Zhai J, Accerbi M, Jeong DH, Park S, Meyers BC, Jorgensen RA, Green PJ. 2009. Distinct extremely abundant sirnas associated with cosuppression in petunia. RNA 15: 1965-1970.

Dinh TT, O'Leary M, Won SY, Li S, Arroyo L, Liu X, Defries A, Zheng B, Cutler SR, Chen X. 2013. Generation of a luciferase-based reporter for chh and cg DNA methylation in arabidopsis thaliana. Silence 4: 1 .

Dolinoy DC. 2008. The agouti mouse model: An epigenetic biosensor for nutritional and environmental alterations on the fetal epigenome. Nutr. Rev. 66 Suppl. 1: S7-11.

Dolinoy DC, Weidman JR, Waterland RA, Jirtle RL. 2006. Maternal genistein alters coat color and protects avy mouse offspring from obesity by modifying the fetal epigenome. Environ. Health Perspect. 114: 567-572.

Dowen RH, Pelizzola M, Schmitz RJ, Lister R, Dowen JM, Nery JR, Dixon JE, Ecker JR. 2012. Widespread dynamic DNA methylation in response to biotic stress. Proc. Natl. Acad. Sci. USA 109: E2183-2191.

Durand S, Bouche N, Perez Strand E, Loudet O, Camilleri C. 2012. Rapid establishment of genetic incompatibility through natural epigenetic variation. Curr. Biol. 22: 326-331.

Erhard KF, Jr., Stonaker JL, Parkinson SE, Lim JP, Hale CJ, Hollick JB. 2009. Rna polymerase iv functions in paramutation in zea mays. Science 323: 1201-1205.

Fujimoto R, Kinoshita Y, Kawabe A, Kinoshita T, Takashima K, Nordborg M, Nasrallah ME, Shimizu KK, Kudoh H, Kakutani T. 2008. Evolution and control of imprinted fwa genes in the genus arabidopsis. PLoS Genet. 4: e1000048.

Gehring M, Huh JH, Hsieh TF, Penterman J, Choi Y, Harada JJ, Goldberg RB, Fischer RL. 2006. Demeter DNA glycosylase establishes medea polycomb gene self-imprinting by allele-specific demethylation. Cell 124: 495-506.

Gehring M, Reik W, Henikoff S. 2009. DNA demethylation by DNA repair. Trends Genet. 25: 82-90.

Haag JR, Pikaard CS. 2011. Multisubunit rna polymerases iv and v: Purveyors of non-coding rna for plant gene silencing. Nat. Rev. Mol. Cell Biol. 12: 483-492.

Haig D. 2004. The (dual) origin of epigenetics. Cold Spring Harbor Symp. Quant. Biol. 69: 67-70.

Hale CJ, Erhard KF, Jr., Lisch D, Hollick JB. 2009. Production and processing of sirna precursor transcripts from the highly repetitive maize genome. PLoS Genet. 5: e1000598.

Haring M, Bader R, Louwers M, Schwabe A, van Driel R, Stam M. 2010. The role of DNA methylation, nucleosome occupancy and histone modifications in paramutation. Plant J. 63: 366-378

Henderson IR, Jacobsen SE. 2007. Epigenetic inheritance in plants. Nature 447: 418-424.

Hollick JB, Kermicle JL, Parkinson SE. 2005. Rmr6 maintains meiotic inheritance of paramutant states in zea mays. Genetics 171: 725-740.

Holtorf S, Apel K, Bohlmann H. 1995. Comparison of different constitutive and inducible promoters for the overexpression of transgenes in arabidopsis thaliana. Plant Mol. Biol. 29: 637-646.

Hsieh TF, Ibarra CA, Silva P, Zemach A, Eshed-Williams L, 
Fischer RL, Zilberman D. 2009. Genome-wide demethylation of arabidopsis endosperm. Science 324: 1451-1454.

Hsieh TF, Shin J, Uzawa R, Silva P, Cohen S, Bauer MJ, Hashimoto M, Kirkbride RC, Harada JJ, Zilberman D, Fischer RL. 2011. Regulation of imprinted gene expression in arabidopsis endosperm. Proc. Natl. Acad. Sci. USA 108: 1755-1762.

Ito $\mathrm{H}$, Gaubert $\mathrm{H}$, Bucher $\mathrm{E}$, Mirouze $\mathrm{M}$, Vaillant I, Paszkowski J. 2011. An sirna pathway prevents transgenerational retrotransposition in plants subjected to stress. Nature 472: 115-119.

Jacobsen SE, Meyerowitz EM. 1997. Hypermethylated superman epigenetic alleles in arabidopsis. Science 277: 1100-1103.

Jeddeloh JA, Stokes TL, Richards EJ. 1999. Maintenance of genomic methylation requires a swi2/snf2-like protein. Nat. Genet. 22: 94-97.

Jin X, Pang Y, Jia F, Xiao G, Li Q, Zhu Y. 2013. A potential role for chh DNA methylation in cotton fiber growth patterns. PLoS One 8: e60547.

Johannes F, Porcher E, Teixeira FK, Saliba-Colombani V, Simon M, Agier N, Bulski A, Albuisson J, Heredia F, Audigier P, Bouchez D, Dillmann C, Guerche P, Hospital F, Colot V. 2009. Assessing the impact of transgenerational epigenetic variation on complex traits. PLoS Genet. 5: e1000530.

Johnson LM, Bostick M, Zhang X, Kraft E, Henderson I, Callis J, Jacobsen SE. 2007. The sra methyl-cytosinebinding domain links DNA and histone methylation. Curr. Biol. 17: 379-384.

Jones JD, Dunsmuir P, Bedbrook J. 1985. High level expression of introduced chimaeric genes in regenerated transformed plants. EMBO J. 4: 2411-2418.

Kaminen-Ahola N, Ahola A, Maga M, Mallitt KA, Fahey P, Cox TC, Whitelaw E, Chong S. 2010. Maternal ethanol consumption alters the epigenotype and the phenotype of offspring in a mouse model. PLoS Genet. 6: e1000811.

Kinoshita T, Miura A, Choi Y, Kinoshita Y, Cao X, Jacobsen SE, Fischer RL, Kakutani T. 2004. One-way control of fwa imprinting in arabidopsis endosperm by DNA methylation. Science 303: 521-523.

Kinoshita Y, Saze H, Kinoshita T, Miura A, Soppe WJ, Koornneef M, Kakutani T. 2007. Control of fwa gene silencing in arabidopsis thaliana by sine-related direct repeats. Plant J. 49: 38-45.

Kucharski R, Maleszka J, Foret S, Maleszka R. 2008. Nutritional control of reproductive status in honeybees via DNA methylation. Science 319: 1827-1830.

Lang-Mladek C, Popova O, Kiok K, Berlinger M, Rakic B, Aufsatz W, Jonak C, Hauser MT, Luschnig C. 2010. Transgenerational inheritance and resetting of stressinduced loss of epigenetic gene silencing in arabidopsis. Mol. Plant 3: 594-602.

Latzel V, Allan E, Bortolini Silveira A, Colot V, Fischer M, Bossdorf O. 2013. Epigenetic diversity increases the productivity and stability of plant populations. Nat. Commun. 4: 2875.

Latzel V, Zhang Y, Karlsson Moritz K, Fischer M, Bossdorf O. 2012. Epigenetic variation in plant responses to defence hormones. Ann. Bot. 110: 1423-1428.

Law JA, Jacobsen SE. 2010. Establishing, maintaining and modifying DNA methylation patterns in plants and animals. Nat. Rev. Genet. 11: 204-220.

Li X, Wang X, He K, Ma Y, Su N, He H, Stolc V, Tongprasit W, Jin W, Jiang J, Terzaghi W, Li S, Deng XW. 2008. High-resolution mapping of epigenetic modifications of the rice genome uncovers interplay between DNA methylation, histone methylation, and gene expression. Plant Cell 20: 259-276.

Lindroth AM, Cao X, Jackson JP, Zilberman D, McCallum CM, Henikoff S, Jacobsen SE. 2001. Requirement of chromomethylase 3 for maintenance of cpxpg methylation. Science 292: 2077-2080.

Lippman ZL. 2004. Role of transposable elements in heterochromatin and epigenetic control. Nature 430: 471-476.

Lira-Medeiros CF, Parisod C, Fernandes RA, Mata CS, Cardoso MA, Ferreira PC. 2010. Epigenetic variation in mangrove plants occurring in contrasting natural environment. PLoS One 5: e10326.

Luna E, Bruce TJ, Roberts MR, Flors V, Ton J. 2012. Next-generation systemic acquired resistance. Plant Physiol. 158: 844-853.

Maeder ML, Angstman JF, Richardson ME, Linder SJ, Cascio VM, Tsai SQ, Ho QH, Sander JD, Reyon D, Bernstein BE, Costello JF, Wilkinson MF, Joung JK. 2013. Targeted DNA demethylation and activation of endogenous genes using programmable tale-tet 1 fusion proteins. Nat. Biotechnol. 31: 1137-1142.

Manning K, Tor M, Poole M, Hong Y, Thompson AJ, King GJ, Giovannoni JJ, Seymour GB. 2006. A naturally occurring epigenetic mutation in a gene encoding an sbp-box transcription factor inhibits tomato fruit ripening. Nat. Genet. 38: 948-952. 
Martel C, Vrebalov J, Tafelmeyer P, Giovannoni JJ. 2011. The tomato mads-box transcription factor ripening inhibitor interacts with promoters involved in numerous ripening processes in a colorless nonripening-dependent manner. Plant Physiol. 157: 1568-1579.

Martin A, Troadec C, Boualem A, Rajab M, Fernandez R, Morin H, Pitrat M, Dogimont C, Bendahmane A. 2009. A transposon-induced epigenetic change leads to sex determination in melon. Nature 461: 1135-1138.

Mathieu O, Reinders J, Caikovski M, Smathajitt C, Paszkowski J. 2007. Transgenerational stability of the arabidopsis epigenome is coordinated by cg methylation. Cell 130: 851-862.

Matzke M, Kanno T, Daxinger L, Huettel B, Matzke AJ. 2009. Rna-mediated chromatin-based silencing in plants. Curr. Opin. Cell Biol. 21: 367-376.

Mendenhall EM, Williamson KE, Reyon D, Zou JY, Ram O, Joung JK, Bernstein BE. 2013. Locus-specific editing of histone modifications at endogenous enhancers. Nat. Biotechnol. 31: 1133-1136.

Mirouze M, Reinders J, Bucher E, Nishimura T, Schneeberger K, Ossowski S, Cao J, Weigel D, Paszkowski J, Mathieu O. 2009. Selective epigenetic control of retrotransposition in arabidopsis. Nature 461: 427-430.

Miura K, Agetsuma M, Kitano H, Yoshimura A, Matsuoka M, Jacobsen SE, Ashikari M. 2009. A metastable dwarf1 epigenetic mutant affecting plant stature in rice. Proc. Natl. Acad. Sci. USA 106: 11218-11223.

Miura K, Ikeda M, Matsubara A, Song XJ, Ito M, Asano K, Matsuoka M, Kitano H, Ashikari M. 2010. Osspl14 promotes panicle branching and higher grain productivity in rice. Nat. Genet. 42: 545-549.

Napoli C, Lemieux C, Jorgensen R. 1990. Introduction of a chimeric chalcone synthase gene into petunia results in reversible co-suppression of homologous genes in trans. Plant Cell 2: 279-289.

Noutoshi Y, Ikeda M, Saito T, Osada H, Shirasu K. 2012. Sulfonamides identified as plant immune-priming compounds in high-throughput chemical screening increase disease resistance in arabidopsis thaliana. Frontier. Plant Sci. 3: 245.

Peach C, Velten J. 1991. Transgene expression variability (position effect) of cat and gus reporter genes driven by linked divergent t-DNA promoters. Plant Mol. Biol. 17: 49-60.

Pecinka A, Dinh HQ, Baubec T, Rosa M, Lettner N, Mittelsten Scheid O. 2010. Epigenetic regulation of repetitive elements is attenuated by prolonged heat stress in arabidopsis. Plant Cell 22: 3118-3129.

Que Q, Wang HY, English JJ, Jorgensen RA. 1997. The frequency and degree of cosuppression by sense chalcone synthase transgenes are dependent on transgene promoter strength and are reduced by premature nonsense codons in the transgene coding sequence. Plant Cell 9: 13571368.

Reik W. 2007. Stability and flexibility of epigenetic gene regulation in mammalian development. Nature 447: 425-432.

Reinders J, Wulff BB, Mirouze M, Mari-Ordonez A, Dapp M, Rozhon W, Bucher E, Theiler G, Paszkowski J. 2009. Compromised stability of DNA methylation and transposon immobilization in mosaic arabidopsis epigenomes. Genes Dev. 23: 939-950.

Richards EJ. 2006. Inherited epigenetic variation--revisiting soft inheritance. Nature reviews. Genetics 7: 395-401.

Richards EJ. 2011. Natural epigenetic variation in plant species: A view from the field. Curr. Opin. Plant Biol. 14: 204-209.

Roux F, Colome-Tatche M, Edelist C, Wardenaar R, Guerche P, Hospital F, Colot V, Jansen RC, Johannes F. 2011. Genome-wide epigenetic perturbation jump-starts patterns of heritable variation found in nature. Genetics 188: 1015-1017.

Saze H, Kakutani T. 2007. Heritable epigenetic mutation of a transposon-flanked arabidopsis gene due to lack of the chromatin-remodeling factor ddm1. EMBO J. 26: 36413652.

Saze H, Shiraishi A, Miura A, Kakutani T. 2008. Control of genic DNA methylation by a jmjc domain-containing protein in arabidopsis thaliana. Science 319: 462-465.

Schmitz RJ, Schultz MD, Lewsey MG, O'Malley RC, Urich MA, Libiger O, Schork NJ, Ecker JR. 2011. Transgenerational epigenetic instability is a source of novel methylation variants. Science 334: 369-373.

Schnable PS, Ware D, Fulton RS, Stein JC, Wei F, Pasternak S, Liang C, Zhang J, Fulton L, Graves TA, et al. 2009. The b73 maize genome: Complexity, diversity, and dynamics. Science 326: 1112-1115.

Slotkin RK, Vaughn M, Borges F, Tanurdzic M, Becker JD, Feijo JA, Martienssen RA. 2009. Epigenetic reprogramming and small rna silencing of transposable elements in pollen. Cell 136: 461-472.

Soppe WJJ, Jacobsen SE, Alonso-Blanco C, Jackson JP, Kakutani T, Koornneef M, Peeters AJM. 2000. The late 
flowering phenotype of fwa mutants is caused by gain-of-function epigenetic alleles of a homeodomain gene. Mol. Cell 6: 791-802.

Stam M, Belele C, Dorweiler JE, Chandler VL. 2002. Differential chromatin structure within a tandem array $100 \mathrm{~kb}$ upstream of the maize b1 locus is associated with paramutation. Genes Dev. 16: 1906-1918.

Stonaker JL, Lim JP, Erhard KF, Jr., Hollick JB. 2009. Diversity of pol iv function is defined by mutations at the maize rmr7 locus. PLoS Genet. 5: e1000706.

Tittel-Elmer M, Bucher E, Broger L, Mathieu O, Paszkowski J, Vaillant I. 2010. Stress-induced activation of heterochromatic transcription. PLoS Genet. 6: e1001175.

Tsukahara S, Kobayashi A, Kawabe A, Mathieu O, Miura A, Kakutani T. 2009. Bursts of retrotransposition reproduced in arabidopsis. Nature 461: 423-426.

Vandegehuchte MB, Lemiere F, Vanhaecke L, Vanden Berghe W, Janssen CR. 2010. Direct and transgenerational impact on daphnia magna of chemicals with a known effect on DNA methylation. Comp. Biochem. Phys. C. 151: 278-285.

Verhoeven KJ, Jansen JJ, van Dijk PJ, Biere A. 2010. Stress-induced DNA methylation changes and their heritability in asexual dandelions. New Phytol. 185: 1108 $-1118$.

Vongs A, Kakutani T, Martienssen RA, Richards EJ. 1993. Arabidopsis thaliana DNA methylation mutants. Science 260: 1926-1928.

Wang X, Elling AA, Li X, Li N, Peng Z, He G, Sun H, Qi Y, Liu XS, Deng XW. 2009. Genome-wide and organspecific landscapes of epigenetic modifications and their relationships to mrna and small rna transcriptomes in maize. Plant Cell 21: 1053-1069.

Wassenegger M, Heimes S, Riedel L, Sanger HL. 1994. Rna-directed de novo methylation of genomic sequences in plants. Cell 76: 567-576.

Waterland RA, Jirtle RL. 2003. Transposable elements: targets for early nutritional effects on epigenetic gene regulation. Mol. Cell. Biol. 23: 5293-5300.

Waterland RA, Travisano M, Tahiliani KG. 2007. Dietinduced hypermethylation at agouti viable yellow is not inherited transgenerationally through the female. FASEB J. 21: 3380-3385.

Waters AJ, Bilinski P, Eichten SR, Vaughn MW, Ross-Ibarra J, Gehring M, Springer NM. 2013. Comprehensive analysis of imprinted genes in maize reveals allelic variation for imprinting and limited conservation with other species. Proc. Natl. Acad. Sci. USA 110: 1963919644.

Waters AJ, Makarevitch I, Eichten SR, Swanson-Wagner RA, Yeh CT, Xu W, Schnable PS, Vaughn MW, Gehring M, Springer NM. 2011. Parent-of-origin effects on gene expression and DNA methylation in the maize endosperm. Plant Cell 23: 4221-4233.

Watt F, Molloy PL. 1988. Cytosine methylation prevents binding to DNA of a hela cell transcription factor required for optimal expression of the adenovirus major late promoter. Genes Dev. 2: 1136-1143.

Weaver IC, Cervoni N, Champagne FA, D'Alessio AC, Sharma S, Seckl JR, Dymov S, Szyf M, Meaney MJ. 2004. Epigenetic programming by maternal behavior. Nat. Neurosci. 7: 847-854.

Zemach A, Kim MY, Silva P, Rodrigues JA, Dotson B, Brooks MD, Zilberman D. 2010a. Local DNA hypomethylation activates genes in rice endosperm. Proc. Natl. Acad. Sci. USA 107: 18729-18734.

Zemach A, McDaniel IE, Silva P, Zilberman D. 2010b. Genome-wide evolutionary analysis of eukaryotic DNA methylation. Science 328: 916-919.

Zhang H, Deng X, Miki D, Cutler S, La H, Hou YJ, Oh J, Zhu JK. 2012a. Sulfamethazine suppresses epigenetic silencing in arabidopsis by impairing folate synthesis. Plant Cell 24: 1230-1241.

Zhang L, Cheng Z, Qin R, Qiu Y, Wang JL, Cui X, Gu L, Zhang X, Guo X, Wang D, Jiang L, Wu CY, Wang H, Cao X, Wan J. 2012b. Identification and characterization of an epi-allele of fiel reveals a regulatory linkage between two epigenetic marks in rice. Plant Cell 24: 4407-4421.

Zhang X, Yazaki J, Sundaresan A, Cokus S, Shan SW, Chen H, Henderson IR, Shinn P, Pellegrini M, Jacobsen SE, Ecker JR. 2006. Genome-wide high resolution mapping and functional analysis of DNA methylation in arabidopsis. Cell 126: 1189-1206.

Zhang YY, Fischer M, Colot V, Bossdorf O. 2013. Epigenetic variation creates potential for evolution of plant phenotypic plasticity. New Phytol. 197: 314-322.

Zilberman D, Gehring M, Tran RK, Ballinger T, Henikoff S. 2007. Genome-wide analysis of arabidopsis thaliana DNA methylation uncovers an interdependence between methylation and transcription. Nature Genet. 39: 61-69. 